\title{
Aprimoramento da argumentação por meio de atividades experimentais com abordagem sociocultural no ensino de corrosão
}

Improvement of argumentation through experimental activities with a sociocultural approach in teaching corrosion

Natália de Paiva Diniz ${ }^{1}$

Denis Felipe de Barros ${ }^{2}$

Alice Assis ${ }^{3}$

\section{Resumo}

Esta pesquisa analisa a interação entre os alunos e entre o professor e os alunos, mediante a aplicação de uma sequência didática pautada em atividades experimentais sobre o tema corrosão, com o intuito de verificar de que forma essa interação entre os sujeitos contribui para o aprimoramento dos argumentos dos alunos com relação aos conceitos abordados. Os instrumentos de análise foram constituídos pelas transcrições das videogravações das aulas, pelas respostas dos grupos de alunos às questões associadas aos experimentos realizados no decorrer das aulas, e pelas respostas das duplas de alunos às questões da atividade avaliativa realizada ao final do processo. Os resultados da análise mostraram que tal interação possibilitou um espaço de diálogo em que os alunos participaram ativamente, culminando em um aprimoramento da sua argumentação.

Palavras-chave: ensino de química; argumentação; experimentação.

\section{Abstract}

This research analyzes the interaction between students and between teacher and students, by applying a didactic sequence based on experimental activities on the subject of corrosion, in order to verify how this interaction between subjects contributes to the improvement of students' arguments regarding the concepts covered. The instruments of analysis were constituted by the transcriptions of the video recordings of the classes, the responses of the groups of students to the questions associated with the experiments carried out during the classes, and the responses of the pairs of students to the questions of the evaluative activity carried out at the end of the process. The results of the analysis showed that such interaction enabled a space for dialogue in which the students actively participated, culminating in an improvement of the arguments of them.

Keywords: chemistry teaching; argumentation; experimentation.

\footnotetext{
${ }^{1}$ Universidade Estadual Paulista | nataliapdiniz@gmail.com

2 Universidade de São Paulo | denis.barros@usp.br

3 Universidade Estadual Paulista | alice.assis@unesp.br
} 


\section{Introdução}

Possibilitar que o aluno interaja ativamente em aulas de química, de forma que tenha contato com diversas formas de pensar, pode ser um fator importante para promover seu interesse na aprendizagem dos conteúdos. Considerar a sala de aula como um ambiente dinâmico no que se refere às interações entre aluno-aluno e alunos-professor, segundo Vygotsky (1991), pode viabilizar o desenvolvimento cognitivo dos estudantes.

Nessa perspectiva, o conhecimento se constrói por meio das interações entre os alunos, o professor e o saber, em um ambiente dinâmico e dialógico. Essas interações são geralmente mediadas pela linguagem que, de acordo com Vygotsky (1991), se relaciona diretamente com o desenvolvimento do pensamento, uma vez que possibilita a análise, a abstração e a generalização de situações, criando significados. Segundo esse autor,

A relação entre o pensamento e a palavra não é uma coisa, mas um processo, um movimento contínuo de vaivém entre a palavra e o pensamento; nesse processo a relação entre o pensamento e a palavra sofre alterações que, também elas, podem ser consideradas como um desenvolvimento no sentido funcional. As palavras não se limitam a exprimir o pensamento: é por elas que este acede à existência (VYGOTSKY, 1991, p. 108).

Ao estudar essas relações entre o pensamento e a linguagem, Vygotsky (2001) afirma que ambos passam por mudanças ao longo da vida das pessoas. Mesmo que tenham origens diversas e se desenvolvam de forma independente, o pensamento e a linguagem se encontram e dão origem a modos mais sofisticados de funcionamento psicológico, devido à inserção do indivíduo em seu meio cultural (OLIVEIRA, 2010). Nesse sentido, o processo de desenvolvimento cognitivo do sujeito se dá por meio da interação social (VYGOTSKY, 2001). Podemos, então, dizer que o processo de construção de argumentos pode ser aprimorado na medida em que os alunos interagem socialmente entre si e com o professor.

Dentre os principais aspectos considerados positivos para a participação dos alunos em situações argumentativas nas pesquisas, elencados por Vieira e Nascimento (2009), estão: as explicitações de diferentes pontos de vista; a crítica mútua dos posicionamentos; a tomada de consciência dos alunos sobre suas ideias e as lacunas e inconsistências nelas presentes; as tensões e negociações entre o conhecimento cotidiano e o conhecimento científico; e a explicitação, a construção e a reconstrução do pensamento dos alunos.

Para isso, é importante a criação de um ambiente que favoreça a interação entre esses protagonistas. A experimentação pode ser um recurso favorável ao diálogo em sala de aula, possibilitando que os estudantes construam argumentos científicos. Nessa perspectiva, Leal et al. (2019) verificaram que a experimentação investigativa em eletroquímica possibilitou exercitar e desenvolver habilidades argumentativas que, por consequência, levaram ao desenvolvimento do pensamento crítico e da autonomia dos alunos de uma escola federal de ensino médio integrado ao técnico de Santa Maria, no Rio Grande do Sul.

O laboratório - e a experimentação, de forma geral - segundo Campos e Araújo (2019), é visto como uma estratégia que possibilita o desenvolvimento de conceitos e de habilidades procedimentais, permitindo, inclusive, a problematização de diferentes domínios do conhecimento, propiciando ainda que se desenvolvam trabalhos em equipe. Os autores também ressaltam o caráter motivador da experimentação no ensino de ciências, destacando o seu potencial para "um ambiente cognitivo fértil para aprender os conceitos científicos" (p. 226). No entanto, é fundamental planejá-la de forma que a abordagem 
superficial dessa estratégia - ligada basicamente à motivação e à ilustração de conceitos seja superada, como apontam Hodson (1994) e Gonçalves e Galiazzi (2006).

Nesta pesquisa, buscamos analisar o processo de interação entre os alunos e entre o professor e os alunos, mediante a aplicação de uma sequência didática pautada em atividades experimentais com abordagem sociocultural (GONÇALVES; GALIAZZI, 2006), com o intuito de verificarmos de que forma essa interação contribuiu para o aprimoramento dos argumentos dos alunos relativos aos conceitos de corrosão. Corresponde a um Estudo de Caso, pois é uma "investigação empírica que investiga um fenômeno contemporâneo dentro de seu contexto de vida real" (YIN, 2001, p. 32).

\section{Atividades experimentais com abordagem sociocultural e a construção de argumentos}

O ambiente experimental pode instigar no aluno um espírito investigativo, ao propiciar que se estabeleça um processo lógico, sistemático, analítico e argumentativo (GALIAZZI et al., 2001). Segundo esses autores, é necessária a explicitação do próprio pensamento dos participantes, por meio do diálogo oral ou escrito. Para isso, é importante que o professor promova um ambiente favorável em sala de aula, que pode ser possível por meio da abordagem experimental pautada na teoria sociocultural de Vygotsky (1991).

Segundo Vygotsky (1991), a aprendizagem possui caráter social e histórico. Portanto, as interações entre os indivíduos são essenciais para a compreensão das representações mentais de seu grupo social. Ao entrar em contato com os diversos argumentos em sala de aula, o estudante pode não compreender todas as questões ali discutidas devido às limitações do seu conhecimento. Logo, o papel do professor e dos colegas de classe é essencial para estimular o amadurecimento de processos internos que conduzirão a novas bases de conhecimento, agindo na chamada Zona de Desenvolvimento Proximal (ZDP), definida por Vygotsky como:

[...] a distância entre o nível de desenvolvimento real, que se costuma determinar através da solução independente de problemas, e o nível de desenvolvimento potencial, determinado através da solução de problemas sob a orientação de um adulto ou em colaboração com companheiros mais capazes (VYGOTSKY, 1991, p. 58).

De acordo com Gonçalves e Galiazzi (2006), a abordagem experimental sociocultural possibilita a contextualização do conteúdo, ao trazer discussões sobre os aspectos culturais, econômicos, políticos e sociais para a sala de aula. Além disso, possui características metodológicas que favorecem o processo de aprendizagem dos estudantes, sendo elas o movimento de questionamento, de construção de argumentos e de comunicação e validação do conhecimento construído (MORAES; GALIAZZI; RAMOS, 2002).

O movimento de questionamento pode ser utilizado em diversos momentos em sala de aula, pois viabiliza que o professor acesse os conhecimentos prévios dos estudantes e auxilia na verificação da sua aprendizagem. Para isso, é importante que o professor procure variar as atividades experimentais sobre um mesmo tema, possibilitando a problematização do conhecimento do aluno sobre ele (GONÇALVES; GALIAZZI, 2006).

A construção de argumentos, segundo Gonçalves e Galiazzi (2006), deve ser inserida nas atividades experimentais em um contexto dialógico, mediante a interação dos sujeitos 
envolvidos (professor e alunos) no processo de análise do fenômeno e no debate das hipóteses construídas para justificar os resultados, durante todo o processo da atividade experimental. Mesmo entendendo que a participação individual é importante, o trabalho em grupo favorece a construção dos argumentos, que está inserida em um contexto de dialógico (GONÇALVES; GALIAZZI, 2006).

A comunicação e validação dos argumentos construídos é um momento de sistematização dos conhecimentos pelos alunos, que pode ser realizado de forma escrita ou dialogada. Gonçalves e Galiazzi (2006) indicam que a produção escrita é uma forma de fortalecer os argumentos defendidos, sendo importante que "os alunos se organizem em grupos ou individualmente para sintetizarem por escrito as aprendizagens construídas com a atividade experimental" (p. 249).

Na presente pesquisa, elaboramos uma sequência didática de modo a explorar essas características metodológicas da atividade experimental com abordagem sociocultural, estimulando um ambiente favorável ao diálogo, a fim de verificarmos se há o aprimoramento da argumentação dos alunos com relação aos conceitos de corrosão.

\section{A pesquisa}

Desenvolvemos a sequência didática no contexto da disciplina Tecnologia dos Materiais, Máquinas e Ferramentas, ministrada no curso Técnico em Mecânica de uma escola de ensino médio integrado à educação profissional técnica na cidade de Guaratinguetá, São Paulo. No seu Plano de Curso, consta que a missão do colégio é preparar o aluno para o exercício de uma profissão técnica, conscientizando-o da importância do respeito, da ética e da responsabilidade por todas as suas ações. Nessa perspectiva, uma sequência didática pautada na abordagem experimental sociocultural possibilita a discussão dos conceitos científicos permeada por reflexões acerca do impacto das ações do ser humano na sociedade. Participaram das aulas 24 alunos do $3^{\circ}$ ano do ensino médio da referida escola, com faixa etária entre 17 a 18 anos.

Para viabilizar esse processo, trabalhamos com a temática corrosão, uma vez que os materiais metálicos são essenciais para o setor industrial, porém estão susceptíveis a interações com o meio em que estão inseridos, o que pode levar a uma degradação de suas propriedades, acarretando o processo de corrosão (GENTIL, 2007). Essa deterioração pode causar sérios problemas ambientais, como vazamento em oleodutos, levando contaminação ao lençol freático e gerando sérios prejuízos nas instalações industriais.

Elaboramos uma sequência didática pautada em atividades experimentais, com as características metodológicas da abordagem sociocultural, realizadas em um total de 6 aulas de 50 minutos, divididas em três semanas, sendo que em cada semana realizamos um encontro de duas aulas. O Quadro 1 apresenta uma síntese das atividades realizadas em cada encontro e os momentos em que elas foram realizadas em aula.

Como pode ser verificado no Quadro 1, os alunos realizaram uma série de três experimentos, em momentos distintos. Cada experimento foi proposto com um objetivo diferente, porém, os três correspondem a variações de atividades experimentais semelhantes, possibilitando a problematização do conhecimento dos estudantes sobre o tema (GONÇALVES; GALIAZZI, 2006). Ressaltamos que para a realização dos experimentos os alunos foram divididos em cinco grupos, sendo quatro grupos de cinco integrantes e um grupo de quatro estudantes. 
Quadro 1 - Síntese das atividades realizadas durante a sequência didática.

\begin{tabular}{|c|c|c|}
\hline $\begin{array}{c}\text { Encontro } \\
\text { (2 aulas) }\end{array}$ & $\begin{array}{c}\text { Tempo } \\
\text { (min.) }\end{array}$ & Atividade Realizada \\
\hline $1^{0}$ & $\begin{array}{l}14-36 \\
36-48 \\
48-54 \\
54-75 \\
75-85 \\
85-95 \\
95-100\end{array}$ & $\begin{array}{l}\text { Levantamento das concepções prévias dos alunos sobre corrosão e como ela afeta os } \\
\text { materiais, por meio de questionamentos. } \\
\text { Contextualização socioambiental: indagação aos alunos sobre o porquê é importante } \\
\text { estudar e prevenir a corrosão; Apresentação e discussão de duas notícias sobre os } \\
\text { impactos ambientais, sociais e econômicos causados pela corrosão (derramamento de } \\
\text { petróleo no mar e explosão de uma tubulação de gás). } \\
\text { Explicaçães do professor sobre as atividades experimentais que serão realizadas; Divisão } \\
\text { dos grupos; Entrega do roteiro experimental, da tabela de potencial de redução/oxidação e } \\
\text { dos materiais para a realização do experimento A; Leitura do roteiro e esclarecimento de } \\
\text { dúvidas sobre a atividade; Alerta sobre questões de segurança durante a manipulação de } \\
\text { produtos químicos. } \\
\text { Realização do experimento A pelos grupos; Discussão dos grupos sobre o fenômeno } \\
\text { observado de acordo com as questões contidas no roteiro experimental; Resposta por } \\
\text { escrito dos alunos às questões contidas no roteiro. } \\
\text { Socialização das observações e hipóteses criadas pelos grupos, por meio de uma discussão } \\
\text { mediada pelo professor. } \\
\text { Organização da sala pelo professor para a realização do experimento B: recolhimento dos } \\
\text { materiais utilizados anteriormente e entrega dos materiais e roteiros a serem utilizados; } \\
\text { Reforço do alerta sobre o cuidado com a segurança durante a manipulação de produtos } \\
\text { químicos. } \\
\text { Realização do experimento B pelos grupos; Discussão dos grupos sobre o fenômeno } \\
\text { observado de acordo com as questões contidas no roteiro experimental; Resposta por } \\
\text { escrito dos alunos às questões contidas no roteiro. } \\
\text { Socialização das observações e hipóteses criadas pelos grupos, por meio de uma discussão } \\
\text { mediada pelo professor. } \\
\text { Explicação do professor sobre o que será realizado no segundo encontro, com ênfase no } \\
\text { experimento C (este experimento deveria ficar em repouso por, no mínimo, cinco dias. } \\
\text { Assim, ele foi iniciado nesta aula, mas analisado somente na semana seguinte). } \\
\text { Organização da sala pelos alunos e professor. }\end{array}$ \\
\hline $2^{\circ}$ & $\begin{array}{l}0-8 \\
8-66 \\
66-77 \\
79-79 \\
97-97\end{array}$ & $\begin{array}{l}\text { Retomada dos conteúdos vistos na aula anterior, por meio do diálogo com os alunos. } \\
\text { Aula expositiva dialogada sobre: } \\
\text { - os diferentes tipos de corrosão (uniforme, galvânica, em frestas, por pites, intergranular, } \\
\text { por lixiviação seletiva, erosão-corrosão e corrosão sobtensão), utilizando exemplos do } \\
\text { cotidiano dos alunos e das indústrias como forma de contextualização; } \\
\text { - os processos de proteção mais utilizados para a prevenção da corrosão (galvanização e } \\
\text { proteção catódica - ânodo de sacrificio), utilizando a questão ambiental e os impactos } \\
\text { econômicos para contextualização. } \\
\text { O professor relembra que o experimento C foi iniciado na aula anterior, recordando quais } \\
\text { os metais estão em cada um dos seis recipientes e seus respectivos potenciais de oxidação. } \\
\text { Os alunos são questionados pelo professor sobre o que acreditam que aconteceu em cada } \\
\text { um dos recipientes, verificando se suas hipóteses estão de acordo com os resultados } \\
\text { experimentais. } \\
\text { Alunos são avisados de que na próxima aula haverá uma atividade avaliativa em dupla } \\
\text { sobre o tema estudado. }\end{array}$ \\
\hline $3^{\circ}$ & $0-100$ & $\begin{array}{l}\text { Os alunos se dividem em duplas e o professor entrega a atividade avaliativa a ser realizada. } \\
\text { As duplas utilizam o tempo das duas aulas para responder às questões colocadas. }\end{array}$ \\
\hline
\end{tabular}


O experimento A consistia em mergulhar a lâmina de zinco $(Z n)$ em uma solução de sulfato de cobre $\left(\mathrm{CuSO}_{4}\right)$ e mergulhar uma lâmina de cobre $(\mathrm{Cu})$ em uma solução de sulfato de zinco $\left(\mathrm{ZnSO}_{4}\right)$. Após a realização do experimento, os grupos deveriam anotar as observações realizadas. Além disso, solicitamos que os grupos respondessem a três questões norteadoras contidas no roteiro experimental: 1.A) Qual a substância está sendo formada na superfície do metal após algum tempo em contato com a solução? 2.A) O que acontece com as soluções após contato com as placas dos metais? 3.A) Por que você acredita que isso está acontecendo? Após os grupos discutirem e responderem por escrito às perguntas, houve a socialização das respostas por meio de uma discussão mediada pelo professor.

O experimento B consistia em aplicar algumas gotas de ácido clorídrico diluído $(\mathrm{HCl}$ $10 \% \mathrm{v} / \mathrm{v}$ ) em diferentes tipos de metais: ferro, zinco, magnésio, cobre e nióbio, simulando a corrosão ácida em alguns metais. Solicitamos que os alunos anotassem os aspectos macroscópicos observados e discutissem com o grupo o fenômeno ocorrido, segundo três questões norteadoras: 1.B) Explique o fenômeno observado na superfície dos metais utilizados. 2.B) Houve casos em que a interação entre o metal e o ácido foi mais evidente? 3.B) Quais fatores podem ter contribuído para que a reação tenha sido mais ou menos evidente em alguns desses metais? As respostas escritas pelos grupos foram socializadas por meio de uma discussão mediada pelo professor.

O experimento $C$ foi feito de forma demonstrativa, ou seja, o professor conduziu a atividade (OLIVEIRA, 2010). Esse experimento consistia no processo de proteção catódica de uma chapa de ferro mergulhada em solução salina, junto a diferentes metais: cobre, zinco, magnésio, cobre e zinco, magnésio e cobre. O primeiro recipiente continha apenas ferro em solução salina, para que os estudantes pudessem visualizar o processo de corrosão do metal e comparar com os recipientes que continham os possíveis anodos de sacrifício (demais metais ligados ao ferro). Nessa atividade experimental, instigamos a participação dos alunos por meio do diálogo, para que eles formulassem hipóteses e explicações sobre o que aconteceria em cada recipiente.

Após a finalização da aplicação da sequência didática (encontros 1 e 2), elaboramos uma atividade avaliativa escrita para a sistematização dos conhecimentos pelos alunos (encontro 3). Nela, eram descritas situações-problema a serem resolvidas pelos estudantes com base nos conhecimentos abordados durante a sequência didática. Nesse momento, os alunos realizaram a atividade em duplas, totalizando 12 duplas.

Os instrumentos de análise desta pesquisa são constituídos pelas: respostas dos grupos às questões presentes nos roteiros experimentais $A$ e B; respostas das duplas às questões da atividade avaliativa; transcrições das videogravações das aulas.

A abordagem utilizada para a análise dos dados deste trabalho é qualitativa (BOGDAN, BIKLEN, 1991), apresentando as seguintes características: a investigação é realizada de forma descritiva, possuindo o ambiente natural (pessoas, locais e conversas) como fonte de dados; há maior interesse pelo processo que pelo produto, uma vez que busca investigar o fenômeno em toda sua complexidade; e o foco está no estabelecimento de procedimentos e estratégias que permitam a percepção dos sentidos atribuídos pelos sujeitos nas situações abordadas. As categorias de análise foram estabelecidas à priori, tal como evidenciado no item a seguir. 


\section{Categorias de análise}

Para análise dos dados, utilizamos duas formas de categorização dos diálogos transcritos: as categorias de análise das argumentações dos discentes, descritas no Quadro 2, elaboradas por Assis (2005); e as categorias relacionadas às argumentações do docente, extraídas do trabalho de Monteiro (2004), que utilizou aquelas propostas por Boulter e Gilbert (1995), redefinidas por Compiani (1996), detalhadas na Quadro 3.

Quadro 2 - Categorias de análise da argumentação dos discentes.

\begin{tabular}{|l|l|}
\hline \multicolumn{1}{|c|}{ Tipo de argumentação dos discentes } & \multicolumn{1}{|c|}{ Descrição das características } \\
\hline Ação argumentativa elaborativa (AAE) & $\begin{array}{l}\text { Aluno elabora uma explicação para o fenômeno ou } \\
\text { problema em questão. }\end{array}$ \\
\hline Ação argumentativa concordante (AAC) & $\begin{array}{l}\text { Quando o aluno concorda com a explicação elaborada } \\
\text { por outro aluno ou pelo professor. }\end{array}$ \\
\hline $\begin{array}{l}\text { Ação argumentativa questionadora } \\
\text { (AAQ) }\end{array}$ & $\begin{array}{l}\text { O aluno questiona ou discorda de uma colocação } \\
\text { apresentada por outro aluno, pelo professor ou, então, } \\
\text { coloca alguma dúvida para ser esclarecida. }\end{array}$ \\
\hline Ação argumentativa reelaborativa (AAR) & $\begin{array}{l}\text { Quando o aluno reelabora explicações apresentadas } \\
\text { anteriormente para um determinado fenômeno ou } \\
\text { problema. }\end{array}$ \\
\hline Ação argumentativa investigativa (AAlnv) & $\begin{array}{l}\text { O aluno interage com o experimento para fazer } \\
\text { colocações, esclarecer dúvidas, ou, mesmo, para } \\
\text { levantar questões. }\end{array}$ \\
\hline Ação argumentativa de inserção (AAlns) & \begin{tabular}{l} 
O aluno insere algum elemento novo à discussão. \\
\hline
\end{tabular} \\
\hline
\end{tabular}

Fonte: adaptado de Assis (2005).

Os diálogos realizados entre o professor e os alunos durante o $1^{\circ}$ e o $2^{\circ}$ encontros foram videogravados e transcritos. As transcrições foram analisadas segundo as categorias descritas nos Quadros 3 e 4, por meio da identificação de suas características. Além disso, realizamos a triangulação dos diálogos com os dados escritos, provenientes das respostas dos alunos aos questionários e à avaliação. Para facilitar a identificação dos estudantes nas transcrições dos áudios e excertos das atividades escritas, utilizamos os seguintes códigos alfanuméricos: AX, para identificar os alunos; GX, para identificar os grupos; e DX, para identificar as duplas (em que $X$ é um número correspondente ao respectivo aluno/grupo/dupla). O professor é indicado com a letra P. 
Quadro 3 - Categorias de análise da argumentação do docente.

\begin{tabular}{|c|c|c|}
\hline Categoria Geral & Subcategorias & Descrição dos argumentos do professor \\
\hline \multirow[t]{2}{*}{$\begin{array}{l}\text { Argumentação } \\
\text { retórica }\end{array}$} & $\begin{array}{l}\text { de contextualização } \\
\text { (ARC) }\end{array}$ & $\begin{array}{l}\text { Promove o envolvimento dos alunos com o tema, utilizando a sua } \\
\text { autoridade para determinar os objetivos e conteúdos trabalhados. } \\
\text { Embora as ideias dos alunos não sejam levadas em consideração, } \\
\text { essa postura mostra a preocupação do professor com a } \\
\text { aprendizagem dos conceitos ensinados. }\end{array}$ \\
\hline & de exposição (ARE) & $\begin{array}{l}\text { Transmissão de informações que podem subsidiar a compreensão } \\
\text { dos alunos tema. O processo argumentativo é organizado pelo } \\
\text { professor, enquanto o aluno desempenha um papel passivo. }\end{array}$ \\
\hline \multirow{4}{*}{$\begin{array}{l}\text { Argumentação } \\
\text { socrática }\end{array}$} & $\begin{array}{l}\text { de fornecimento de } \\
\text { pistas (ASFP) }\end{array}$ & $\begin{array}{l}\text { Fala do professor que tem por objetivo dirigir o raciocínio dos } \\
\text { alunos, por meio de uma explicação ou de uma série de elementos } \\
\text { que conduzam o aluno a determinadas conclusões e raciocínios. }\end{array}$ \\
\hline & $\begin{array}{l}\text { de remodelamento } \\
\text { (ASRem) }\end{array}$ & $\begin{array}{l}\text { Quando o professor destaca ideias colocadas pelos alunos que } \\
\text { necessitam de maior detalhamento e precisão. Ajustes realizados } \\
\text { pelo professor, preenchendo lacunas conceituais, com base nas } \\
\text { ideias construídas pelos alunos. }\end{array}$ \\
\hline & $\begin{array}{l}\text { de reespelhamento } \\
\text { (ASRee) }\end{array}$ & $\begin{array}{l}\text { Quando o professor autoriza ou não as ideias dos alunos. Usando } \\
\text { de sua autoridade, o professor legitima a ideia do aluno, o que } \\
\text { inibe outras ideias contrárias. Entretanto, por meio de uma } \\
\text { negativa ou da espera por outras respostas, o professor pode } \\
\text { indicar ao aluno que suas ideias não estão corretas. }\end{array}$ \\
\hline & de elucidação (ASE) & $\begin{array}{l}\text { Fala do professor a partir de perguntas colocadas pelos alunos, } \\
\text { com o objetivo de clarear algumas ideias já expostas, mas ainda } \\
\text { não compreendidas. }\end{array}$ \\
\hline \multirow{6}{*}{$\begin{array}{l}\text { Argumentação } \\
\text { dialógica }\end{array}$} & de instigação (ADI) & $\begin{array}{l}\text { Professor incentiva os alunos a explicitarem as suas opiniões, bem } \\
\text { como a iniciarem o processo de interação em sala de aula. }\end{array}$ \\
\hline & $\begin{array}{l}\text { de contraposição } \\
(A D C)\end{array}$ & $\begin{array}{l}\text { Fala do professor que se destina a destacar pontos contraditórios } \\
\text { nos argumentos dos alunos ou, mesmo, gerar conflitos, a fim de } \\
\text { desencadear o confronto entre as ideias expostas. }\end{array}$ \\
\hline & $\begin{array}{l}\text { de organização } \\
(A D O)\end{array}$ & $\begin{array}{l}\text { Professor sistematiza as ideias explicitadas pelos alunos, a fim de } \\
\text { situá-los nas concordâncias e discordâncias, viabilizando novas } \\
\text { interações em sala de aula. Propicia a articulação entre as ideias } \\
\text { colocadas. }\end{array}$ \\
\hline & $\begin{array}{l}\text { de recapitulação } \\
\text { (ADRecap) }\end{array}$ & $\begin{array}{l}\text { Fala do professor que sintetiza todas as ideias discutidas pelos } \\
\text { alunos para finalizar o debate. }\end{array}$ \\
\hline & $\begin{array}{l}\text { de recondução } \\
\text { (ADRecon) }\end{array}$ & $\begin{array}{l}\text { Quando o professor retoma os assuntos considerados pertinentes } \\
\text { para as discussões estabelecidas em sala de aula. Define os limites } \\
\text { e as derivações que não pertencem aos objetivos propostos pela } \\
\text { aula. }\end{array}$ \\
\hline & Fala avaliativa (FA) & $\begin{array}{l}\text { Quando o professor busca a lógica usada pelos alunos em } \\
\text { determinadas afirmações, investigando os motivos pelos quais } \\
\text { externam uma opinião. }\end{array}$ \\
\hline
\end{tabular}

Fonte: adaptado de MONTEIRO (2004).

\section{Resultados e discussão}

Ao realizarem o experimento $A$, os alunos tiveram um momento de reflexão em grupo e responderam às questões norteadoras, descrevendo e criando hipóteses sobre os 
resultados obtidos. O experimento tinha como objetivo a identificação das concepções prévias dos estudantes sobre oxirredução.

Solicitamos que os grupos anotassem suas observações macroscópicas durante a realização do experimento. Nesse momento, os alunos interagiram entre si e com o próprio experimento, descrevendo o que viam (característica da AAInv) e elaborando hipóteses para explicar o fenômeno observado (característica da AAE). Dentre as respostas, selecionamos, como exemplo, as seguintes:

A lâmina de Zn começa a escurecer, já a lâmina de Cu não apresentou mudanças visíveis. O óxido de $Z n$ começa a desprender da lâmina. (G1: alunos $A 3, A 7, A 9, A 18, A 22)$

Recipiente 1: Neste recipiente a lâmina de zinco sofre o processo de oxidação na solução de sulfato de cobre, por ter um maior potencial de oxidação. A solução está recebendo zinco e se tornando $\mathrm{ZnSO}_{4}$. Recipiente 2: não observamos nenhuma reação no recipiente. (G3: alunos A10, A11, A14, A19, A21)

Em ambas as soluções a reação química está demorando, pois demanda tempo. No recipiente com a solução de sulfato de cobre $\left(\mathrm{CuSO}_{4}\right)$, a placa de zinco está sofrendo a deposição de ânions de cobre. No recipiente com a solução de sulfato de zinco não ocorreu reação na placa de cobre. (G5: alunos A2, A6, A12, A23, A24)

Por meio da resposta à questão 1.A, foi possível verificar que os grupos, de formal geral, não possuíam (ou não relacionaram) os conceitos básicos para avaliar o processo de oxirredução analisado. Apenas o grupo G3 afirmou que a substância formada na superfície do zinco metálico era o cobre, enquanto os demais acreditavam ser óxido de zinco ou de cobre.

Entretanto, mesmo que os grupos não tenham associado que o material depositado na lâmina de zinco era o cobre (exceto o grupo G3), todos conseguiram relacionar o valor dos potenciais de redução/oxidação, disponíveis na tabela fornecida, com os resultados observados. O seguinte excerto com a resposta do grupo G1 evidencia que esse grupo explicou com detalhes o que estava acontecendo no recipiente, inserindo os valores dos potenciais tabelados (AAlns). Já, o excerto do grupo G5, assim como os demais grupos, apresenta a informação de forma mais genérica:

Provavelmente, em razão dos potenciais de oxidação. $O E^{0}$ do cobre é 0,34 e o do zinco +0,76. O cobre presente na solução está sendo reduzindo ao $\mathrm{Cu}^{0}$. (G1: alunos $\left.\mathrm{A} 3, \mathrm{~A} 7, \mathrm{~A} 9, \mathrm{~A} 18, \mathrm{~A} 22\right)$

Devido as características químicas dos materiais, como por exemplo, potencial de oxidação e as ligações entre os átomos. (G5: alunos $A 2, A 6$, A12, A23, A24)

Após a etapa de escrita dos alunos, o professor instiga o processo de diálogo em sala para acessar as hipóteses formuladas sobre os resultados. Iniciando com a ADI, o professor incentiva a opinião dos estudantes para promover o processo de interação. Como pode ser verificado no recorte apresentado no Quadro 4, os alunos apresentam algumas informações sobre o que conseguiram visualizar durante o experimento (AAlnv), compatível com os argumentos das respostas dos grupos. 
Quadro 4 - Observações macroscópicas durante o Experimento A.

P: O que vocês observaram nos béqueres?

A12: Esse aqui mudou... [mostrando a placa cobre na solução de $\mathrm{ZnSO}_{4}$ ].

ADI

AAlnv

AAlnv

AAC

A13: Viu! Brigada A11, linda! Te amo!

ASRem

AAC

$A D I$

AAE

AAE

A2: O potencial de oxidação e redução...

Avários: [inaudível].

P: Tá, tudo bem, tem a ver com os potenciais de oxidação e redução, é isso mesmo. [...]

Mesmo que as falas dos estudantes apresentem a $A A E$, não é possível identificar como o potencial de oxidação (explicação para o fenômeno dada pelo aluno) contribuiu para os resultados observados. Por isso, o professor faz a sistematização das ideias dos alunos (ADO), incentivando a opinião de algumas hipóteses levantadas sobre a mudança de coloração da solução, como pode ser observado no recorte da transcrição apresentada no Quadro 5.

Quadro 5 - Levantamento de hipóteses durante o Experimento A.

P: Então a gente tem várias teorias do que aconteceu: primeiro, ficou mais claro porque formou mais água; segundo, foi porque o cobre saiu. Foi isso que eu peguei, certo? Todo mundo concorda?

A14: Água não.

P: Água não. Por que a água não?

ADI

A14: Porque não tem como surgir.

AAE

A3: Porque não tem hidrogênio.

AAE

P: Não tem como surgir água, aham... mas e o cobre? O cobre saiu, mas o cobre saiu de onde?

A7: Do líquido.

ADRecon

A9: Da solução.

AAE

P: Da solução e ele foi pra onde?

$A A C$

$\mathrm{ADI}$

Avários: Pra...

A11: Pra superfície do zinco.

AAE

P: Pra superfície do zinco, isso mesmo. Agora a gente já consegue entender um pouquinho melhor desse negócio que vocês estavam falando do potencial. Vamos ver o que que aconteceu. Qual que é a forma do cobre quando ele está na solução? [...] Qual que é a fórmula do sulfato de cobre?

A9: $\mathrm{CuSO}_{4}$.

P: Então qual que é o número de oxidação do cobre? Vocês lembrando disso aqui em ADRecon química?

Avários: Não.

Nesse momento, vemos que os estudantes começam a discordar (AAQ) de algumas explicações formuladas, como a de que água estaria sendo formada e por isso a solução de sulfato de cobre estava se tornando cada vez mais clara. Dessa forma, o professor utiliza da ADRecon para reconduzir as discussões para o tópico de pertinência. Como consequência, os alunos passam a elaborar novas explicações, que são reconhecidas pelo professor como ponto de partida para um aprofundamento maior nas explicações (ASRee), uma vez que inicia o fornecimento de pistas (ASFP), para que os alunos relacionem a variação do número 
de oxidação de uma substância, com a perda/ganho de elétrons e sua eventual redução/oxidação, conforme recorte apresentado no Quadro 6.

Quadro 6 - Sistematização de ideias levantadas durante o Experimento A.

$\mathrm{P}:[\ldots] \mathrm{SO}_{4}{ }^{2-}$, então $\mathrm{O}$ cobre está $2+. \mathrm{O} \mathrm{Cu}$ na solução tem $\mathrm{O}$ nox $2+$. Então, o que que aconteceu se ele "saiu" da solução, que vocês falaram, e foi pra superfície do zinco. O que aconteceu com ele? Com o número de oxidação?

A9: Ele aumentou... não ele...

A6: Perdeu elétron...

Avários: Não.

A3 e A9: Ele ganhou dois elétrons.

P: Qual que é o número de oxidação que nós comentamos para o ferro, ferro metálico? Todo metal na forma sólida, tem o número de oxidação zero. Então, o cobre foi de cobre 2+ pra cobre 0 , certo. Então o que aconteceu com o número de oxidação?

A6: Diminuiu?

P: Diminuiu. Se diminuiu o que que aconteceu com ele?

ARE, ASFP

A5: Ganhou elétron.

A13: Sofreu oxidação.

AAE

AAE

AAQ

AAE

ASFP

A5: Corroeu.

P: O que que acontece com o número de oxidação: foi de $2+$ pra 0 . Se ele foi de $2+$ pra 0 , o que que aconteceu com ele, ele perdeu ou ganhou elétron?

Avários: Ganhou.

P: Ganhou elétron, porque o elétron tem carga negativa. Então se ele foi de 2+ pra 0 ele recebeu elétron. O número de oxidação diminuiu, então o cobre...

A2: Reduziu.

P: ...reduziu. Isso ai. Se o cobre reduziu, recebendo elétrons. Quem que deu os elétrons pra ele?

A7: $O$ zinco.

$\mathrm{P}: \mathrm{O}$ zinco. E o que que aconteceu com o zinco?

A9: loi pra solução.

AAQ

ASRees,

ADI

AAE

AAE

AAE

ASFP

AAE

ASRem

P: Foi para a solução, oxidou. Então, o zinco tinha nox 0, por ser metálico, e ele foi para a solução na forma $\mathrm{Zn}^{2+}$. Certo, até aí tudo bem? Então, o cobre reduziu e o zinco oxidou. [...] vocês observaram aí que clareou bastante a solução de sulfato de cobre. Se a gente conseguisse enxergar os átomos, a gente ia ver que o zinco está se depositando e formando sulfato de zinco na solução. Então, a placa de zinco, apesar de não ser visível, ela está sendo corroída pelo cobre. Porque está acontecendo um processo de oxidação e redução. Eu ouvi nas discussões dos grupos e a gente pensa muito na corrosão, por causa do ferro, da ferrugem, do $\mathrm{Fe}_{2} \mathrm{O}_{3}$, como oxidação pelo oxigênio e formação da ferrugem. Nem sempre vai formar óxido de alguma coisa, na verdade pode ser qualquer tipo de substância. O que vai falar pra gente o que está acontecendo, quem vai reduzir e quem vai oxidar, é o potencial de redução. Se vocês olharem na tabela o potencial de redução do cobre e do zinco... olha ai quanto é:

A2: $\mathrm{Zn}=-0,76$ e o $\mathrm{Cu}=+0,34$.

AAlns

$\mathrm{P}$ : Como o potencial de redução fala pra gente o que vai acontecer ali? Quem vai oxidar e quem vai reduzir?

A2: Por que o maior potencial de redução reduz?

AAlnv

P: Quem tem o maior potencial de redução reduz. O cobre tem o maior potencial para reduzir, 
Nessa transcrição, podemos observar que o professor organiza os conceitos (ADO) inserindo algumas observações sobre as explicações dos estudantes realizadas durante a discussão dos experimentos nos grupos, como a formação de óxido na placa de zinco (também encontrada nas respostas dos questionários). Mesmo que a teoria da formação do óxido não tenha sido apresentada pelos estudantes durante o diálogo com o professor, a retomada e o esclarecimento dessa hipótese durante a organização dos conceitos puderam auxiliar na desmitificação de que todo processo de oxidação forma algum tipo de óxido.

O experimento B tinha como objetivo a aplicação dos conceitos de oxirredução discutidos na atividade anterior para explicar a corrosão ácida de alguns metais. Assim como no experimento A, solicitamos que os grupos de alunos dialogassem e anotassem suas observações, respondendo às questões norteadores. Por meio das respostas à questão 1.B, foi possível verificar que nenhum dos grupos relacionou a formação de bolhas de gás hidrogênio com a corrosão ácida do metal ${ }^{4}$, porém todos relacionaram de forma qualitativa os fenômenos com os potenciais de oxidação/redução Destacamos abaixo os excertos dos grupos G1, G2 e G4 como exemplo:

Provavelmente houve oxidação, quando comparamos o potencial de oxidação e os materiais que mais reagiram. (G1: alunos A3, A7, A9, A18, A22)

Ocorreu em alguns dos materiais (Mg, Fe, Zn) a oxidação, já em outros não

(Cu, Nb). (G4: alunos A15, A16, A17, A20)

No $\mathrm{Mg} \circ \mathrm{Cl}$ reduziu devido à alta diferença de potencial de redução. (G2: alunos $A 1, A 4, A 5, A 8, A 13)$

Mesmo identificando os materiais que oxidaram e associando o fato com os potenciais de oxidação/redução, os estudantes tiveram dificuldade em reconhecer que o hidrogênio proveniente do ácido clorídrico reduzia, e não o cloro, como mencionado pelo grupo G2, no excerto acima. Isso também fica evidente no recorte da transcrição apresentada no Quadro 7, quando o professor incentiva os alunos a descreverem o que observaram (ADI) e a formular suas explicações (ASRem).

Quadro 7 - Observações macroscópicas durante o Experimento B.

P: E aí gente, o que é que vocês observaram?

ADI

A11: Magnésio é da hora.

AAlnv

A8: O zinco reagiu...

AAlnv

P: O zinco... e o que mais? O que vocês acham que aconteceu?

ASRem

A7: Depende... no cobre não aconteceu nada.

AAlnv

P: Mas vocês perceberam o que formou na superfície do metal? Na hora em que vocês...

ADI

A11: Bolhas.

AAlnv

P: Bolha... de onde que vem a bolha?

ADI

\footnotetext{
${ }^{4}$ Nos casos em que o potencial de redução do hidrogênio (proveniente do ácido clorídrico) é maior que o do metal, ele recebe elétrons do metal, indo de nox +1 para nox 0 , reduzindo-se e, consequentemente, oxidando o metal.
} 
Podemos observar, na transcrição analisada (Quadro 7), que as falas dos alunos apresentam características da AAlnv, o que indica que encontraram dificuldades em formular suas hipóteses para a observação experimental. Dessa forma, o professor passa a oferecer pistas de elementos que auxiliem o raciocínio dos estudantes (ASFP). A partir desse momento, foi possível observar que eles passam a elaborar explicações (AAE) e apresentar alguns questionamentos (AAQ) que são elucidados pelo professor, auxiliando na construção do raciocínio, como pode ser observado no recorte destacado no Quadro 8:

Quadro 8 - Levantamento de hipóteses durante o Experimento B.

\begin{tabular}{|c|c|}
\hline $\begin{array}{l}\text { P: Reação... a reação é exotérmica, mas não é por causa da temperatura. O que é que a gente } \\
\text { colocou no metal? }\end{array}$ & ASFP \\
\hline A2: Ácido, $\mathrm{HCl}$ & AAlnv \\
\hline P: Ácido, $\mathrm{HCl}$. & ASRee \\
\hline A8: Hidrogênio. & AAlnv \\
\hline $\begin{array}{l}\text { P: Se a gente colocou o ácido no metal e aconteceu alguma coisa no metal, aconteceu alguma } \\
\text { coisa também com o HCl. }\end{array}$ & ASFP \\
\hline A3: Ele tá diluído em água, não tá? & AAQ \\
\hline P: Tá diluído em água, a solução é de 10 \%v/v. & ASE \\
\hline A7: Não é o hidrogênio que está soltando? & AAQ \\
\hline $\begin{array}{l}\text { P: Isso, é o hidrogênio. Aquelas bolinhas que a gente observou é o hidrogênio do ácido. Então, } \\
\text { o hidrogênio na solução está na forma... vocês lembram o nox do hidrogênio? } \\
\text { A13: } 1 . \\
\text { A3: }+1 \text {. }\end{array}$ & $\begin{array}{l}\text { ASRee, } \\
\text { ASFP }\end{array}$ \\
\hline $\begin{array}{l}\text { P: Isso, +1. Então, o hidrogênio está na forma ionizável }+1 \text {. Nox }+1 \text {. Quando ele reage, ele vira o } \\
\text { gás o hidrogênio e o que vai acontecer com ele? }\end{array}$ & $\begin{array}{l}\text { ASRee, } \\
\text { ASFP }\end{array}$ \\
\hline A2: Vai virar nox 0, porque é substância simples. & AAE \\
\hline $\begin{array}{l}\text { P: Exatamente. O número de oxidação dele vai ser } 0 \text {, ou seja, o que aconteceu com o } \\
\text { hidrogênio? }\end{array}$ & ASRee, ADI \\
\hline A13: Re... reduziu. & AAE \\
\hline P: Reduziu. & ASRee \\
\hline A13: Exatamente! & AAC \\
\hline P: Ele tinha nox +1 e foi para 0 , então ele reduziu. $O$ que aconteceu com ele? & $A D O, A D I$ \\
\hline A11: Ele ganhou elétron. & $\mathrm{AAE}$ \\
\hline P: Ele ganhou elétron, certo. Esse elétron veio de onde? & ASRem \\
\hline A8: Do metal. & AAE \\
\hline A3: Do material. & AAE \\
\hline
\end{tabular}

Podemos verificar que, no experimento, os alunos puderam relembrar os conceitos básicos de oxirredução (uma vez que é um conteúdo trabalhado no segundo ano do ensino médio). Mesmo conseguindo relacionar os conceitos vistos com os fenômenos observados no experimento B, os alunos ainda apresentaram dificuldades em elaborar suas hipóteses, por não relacionarem quais as substâncias estavam participando efetivamente do processo de corrosão ácida. Dessa forma, o diálogo mediado pelo professor no processo de análise do fenômeno e no debate das hipóteses foi um momento que favoreceu a construção dos argumentos. Além disso, as variações da mesma atividade experimental, possibilitaram a problematização do conhecimento dos estudantes sobre o tema e o aprimoramento dos argumentos dos alunos, que puderam ser verificados por meio da análise da atividade avaliativa em dupla, realizada no terceiro encontro. 
Uma das questões da atividade avaliativa solicitava que os estudantes citassem o tipo de corrosão que uma junta de alumínio e aço sofreriam, como ela ocorre e qual a melhor forma de preveni-la (levando em consideração fatores econômicos). Essa pergunta tinha como objetivo identificar conhecimentos sobre corrosão galvânica (estudada no experimento A), em que os alunos deveriam identificar qual metal sofreria oxidação.

Todas as duplas conseguiram reconhecer o tipo de corrosão que acontece na situação apresentada. Ao justificar como ela ocorre, as duplas identificaram corretamente o material que sofre a corrosão, com exceção das duplas D3, D6 e D12, trocando o material que sofreria oxidação (alumínio) pelo que sofreria redução (ferro), o que indica que podem não ter compreendido os conceitos abordados no experimento A. Destacamos como exemplo as respostas de D3 e D12:

Com a junção de dois flanges de aço e alumínio o aço servirá de um protetor para o alumínio, pois ele tem o potencial de oxidação maior que o do alumínio no caso ele oxidará primeiro deixando o alumínio intacto. (D3: alunos A19 e A20)

A corrosão galvânica ocorre quando dois metais ou ligas diferentes composições são postos em contato, em ambiente propício. A forma mais viável é aplicar proteção catódica nos materiais. [...] O aço ia se oxidar mais em relação ao alumínio, pois ele tem um potencial oxidante maior que o do alumínio. (D12: alunos A23 e A24)

Dentre as respostas apresentadas pelas demais duplas (nove) que, além de reconhecerem o tipo de corrosão descrito no problema, também identificam corretamente qual material sofre oxidação/corrosão, destacamos, como exemplo, os excertos de D2 e D9:

O tipo de corrosão que pode acontecer é a corrosão galvânica, onde os dois materiais metálicos, que possuem composições diferentes, ficam em contato. O metal menos nobre e mais reativo (que é o alumínio) estará sujeito à corrosão e já o mais inerte (o aço que é cátodo) será protegido em relação a corrosão. Para previnir essa corrosão uma forma eficaz e econômica é o revestimento por pintura. (D2: alunos A3 e A18)

Corrosão Galvânica. Neste casso, o aço que tem sua composição majoritária em ferro, vai reduzir, ganhando elétrons. Em consequência o alumínio vai oxidar, perder elétrons. Ela pode ser evitada ao isolar os metais ou utilizar materiais com potenciais de oxidação próximos. (D9: alunos A9 e A4)

Nas respostas das duplas D2 e D9, podemos verificar que, para fortalecer seu argumento, esses estudantes se baseiam nos potenciais de redução/oxidação para prever quem irá perder/receber elétrons. Ainda assim, o excerto não mostra os valores dos potenciais (fornecidos por meio de tabela para consulta). Apenas duas das duplas (D4 e D11) citaram na resposta os valores dos potenciais de redução/oxidação metais, inserindo elementos que fortaleciam ainda mais seus argumentos, como pode ser visto na transcrição das respostas:

[...] Prevenção: Isolamento dos metais ou utilização de metais com potencial de oxidação próximos e proteção catódica (elemento estrutural torna-se cátodos). 
O que acontecerá com os metais: o aço reduzirá e o alumínio oxidará, vêse isso a partir da fórmula a seguir: $\mathrm{Al} \rightarrow \mathrm{Al}^{3+}+3 e$

Justificativa: Isso ocorre pois o potencial de redução do alumínio $(-1,66)$ é menor que o do ferro $(+2,87)$, indicando que entre esses dois componentes o alumínio tem maior tendência a sofrer oxidação e o aço a sofrer redução. (D11: alunos A1 e A13)

[...] 2 - galvânica: ocorre quando dois metais (Al e Aço) dissimilares são postos em contato. O metal menos nobre, no caso o alumínio por apresentar maior potencial de oxidação (Al $\rightarrow+1,66$ e Aço $\rightarrow+0,44$ ), experimentará a corrosão.

3 - galvânica: por meio de uma proteção catódica, pois o isolamento dos metais seria algo inviável. (D4: alunos A11 e A14)

De forma geral, a argumentação dos alunos, para justificar a corrosão nos materiais, foi mais qualitativa (dez duplas) do que quantitativa (duas duplas: D4 e D11, citadas anteriormente). Contudo, a dupla D11 apresentou o valor do potencial de oxidação do cloro ao invés do ferro, mostrando que esses alunos se equivocaram na leitura da tabela. Isso pode sugerir que outras duplas, que não apresentaram dados quantitativos em suas respostas, também podem ter confundido os valores dos potenciais dos metais.

Um outro problema colocado na atividade avaliativa em dupla visava explorar a corrosão ácida, abordada no experimento B. Os alunos deveriam indicar qual seria o melhor material para se utilizar em uma tubulação de ácido clorídrico e justificar a resposta, conforme os conhecimentos de eletroquímica. Por meio da análise das respostas, verificamos que sete das 12 duplas apresentaram dificuldades em determinar o melhor material a ser utilizado na tubulação, mesmo reconhecendo o tipo de corrosão descrita na situação proposta na questão. Destacamos, como exemplo, os seguintes excertos:

[...] O material mais indicado para este caso é o ferro (Fe), pois é o material com maior potencial de redução que o ácido clorídrico e que apresenta um preço acessível. (D10: alunos A6 e A7)

[...] Material indicado seria o aço por causa do ferro presente. O potencial de redução de $\mathrm{Fe}^{2+}$ é $+0,77$. (D9: alunos A9 e A4)

Como pode ser observado, os alunos indicaram o ferro como melhor material a ser usado na tubulação, sugerindo que o conteúdo abordado no experimento B não foi assimilado.

Das 12 respostas apresentadas pelas duplas à essa questão, cinco delas se apresentaram de forma adequada, destacando ao menos um exemplo de metal que poderia ser utilizado na tubulação. Dentre essas respostas, ressaltamos quatro, em que cada dupla justificou a sua hipótese com base no potencial de oxidação/redução em relação ao ácido clorídrico, conforme mostramos a seguir.

Material para a tubulação: Cobre, por este componente não interagir com o $\mathrm{HCl}$ e formar as bolhas de $\mathrm{H}$. ( $\mathrm{H} \rightarrow$ pot. de ox. 0,0 e $\mathrm{Cu} \rightarrow$ pot. de ox. 0,15). (D4: alunos A11 e A14)

[...] pode ser utilizado materiais com potencial de oxidação baixo. Ex: Cu. (D8: alunos A22 e A15). 
Erosão-corrosão: ação combinada de ataques químicos e desgastes mecânicos, consequência de movimento de fluidos.

Prevenção: mudar projeto para eliminar turbulência do líquido de remover partículas e bolhas da tubulação.

(Cu (+ acessível), Pb, Ag, Au (muito caro), F). (Cu (+ acessível), Pb, Ag, Au (muito caro), F). (D6: alunos A2 e A12)

O melhor material para ser utilizado para a tubulação seria o cobre. Entretanto uma possível corrosão é a erosão-corrosão. Desgastaria o cobre ao decorrer do tempo por conta do fluido. A melhor forma de previnir é mudar o projeto para eliminar a turbulência do fluido. (D12: alunos A23 e A24)

Nessas respostas, os alunos identificaram corretamente o cobre como o material que não será oxidado pelo ácido clorídrico e justificaram utilizando a tabela de potencial de redução, algo já realizado no experimento B. A dupla D6, inclusive, citou outros materiais que poderiam ser utilizados, mas que são economicamente inviáveis. Enquanto a dupla D12 apresentou mais detalhes sobre como a tubulação poderia sofrer desgastes devido à forma como foi projetada, inserindo argumentos discutidos durante a aula expositiva dialogada, no segundo encontro.

Pela análise dos dados, verificamos que o argumento dos estudantes foi sendo aprimorado com o andamento das atividades experimentais, por meio do diálogo com o professor e com os demais colegas. A interação entre os sujeitos possibilitou que elementos da investigação científica, como a descrição de aspectos macroscópicos, formulação de hipóteses e análise de dados, aparecessem nos argumentos dos estudantes, o que pode ter contribuído para a construção de conhecimentos sobre corrosão. Isso mostra que, a interação entre alunos-professor e entre aluno-aluno propiciou o aprimoramento dos argumentos dos estudantes frente à temática.

Os alunos A16, A17, A19 e A20, que não demonstraram tal aprimoramento, também foram aqueles que não participaram de forma ativa do diálogo com o professor durante a discussão dos experimentos. Além disso, com exceção do aluno A19, os demais pertenciam ao mesmo grupo ao realizarem as atividades experimentais, o grupo G4. Segundo Vygotsky (1991), a interação somente será efetiva na medida em que as relações entre os parceiros acontecerem na ZDP, sob a orientação de um parceiro mais capaz. Possivelmente, os integrantes do grupo possuíam o mesmo nível de desenvolvimento cognitivo com relação ao tema abordado. O grande número de alunos em sala e a pouca interação desses quatro estudantes no diálogo com o professor pode ter contribuído para que eles não conseguissem aprimorar a argumentação com relação aos conceitos de corrosão.

Mesmo aqueles que apresentaram resoluções consideradas inadequadas em alguma das situações-problema da atividade em duplas (dificuldades em determinar o melhor material a ser utilizado na situação ou confusões com os valores do potencial de redução dos metais) demonstraram ter superado a concepção inicial de corrosão verificada no começo da atividade, a de que ela está atrelada à formação de algum tipo de óxido na superfície do metal (associado à corrosão do ferro, presente no seu cotidiano). Isso mostra que, para melhor compreensão do tema, o tópico oxirredução deve ser abordado com exemplos relacionados ao cotidiano do aluno. 


\section{Considerações finais}

Durante o processo de categorização das transcrições, notamos que os argumentos do professor transitaram, de forma geral, entre: a argumentação dialógica, em que ele incentiva e regula o compartilhamento de ideias, incentivando os estudantes a colocarem suas ideias e desempenharem um papel ativo nas atividades, e a argumentação socrática, em que o professor estrutura as suas falas a partir das colocações dos alunos. Esse direcionamento do professor mostrou-se necessário para guiar os alunos a aspectos a serem tratados, guiando seu raciocínio, a fim de propiciar discussões a respeito dos conteúdos considerados relevantes.

Dessa forma, embora o professor tenha utilizado a argumentação socrática, direcionando o assunto a ser discutido, ele mediou a atividade sem a utilização de uma postura autoritária. Consideramos que essa postura do professor, e os momentos em que foi predominante a utilização de uma argumentação dialógica, estimulou um ambiente favorável de discussões e viabilizou a articulação entre os conteúdos científicos e aspectos socioculturais propiciando a construção dos argumentos por parte dos estudantes.

Além disso, utilizar variações de atividades experimentais que trabalham uma mesma temática sob diferentes perspectivas possibilitou a problematização do conhecimento dos estudantes sobre o tema. Foi possível observar as conexões estabelecidas entre o que foi abordado nos diferentes experimentos, bem como nas respostas dos alunos às situações problema colocadas na atividade final.

Com isso, verificamos que a abordagem experimental sociocultural possibilitou um espaço de diálogo entre os alunos e entre os alunos e o professor, culminando em um aprimoramento da argumentação dos estudantes. Ressaltamos que esse aprimoramento, não foi homogêneo, sendo mais nítido naqueles estudantes em que notamos uma maior participação no decorrer das atividades. Apesar de não ser um dos objetivos desta pesquisa, ressaltamos que o aprimoramento dos argumentos dos alunos pode ser um indício de compreensão dos conhecimentos abordados.

\section{Referências}

ASSIS, A. Leitura, argumentação e ensino de Física: análise da utilização de um texto paradidático em sala de aula. 2005. 286f. Tese (Doutorado em Educação para a Ciência, Área de Concentração: Ensino de Ciências) - Faculdade de Ciências da Universidade Estadual Paulista, Bauru, 2005.

BOGDAN; R. C.; BIKLEN, S. K. Investigação Qualitativa em Educação: uma introdução à teoria e aos métodos. Tradução: ALVAREZ, M. J.; SANTOS, S. B.; BAPTISTA, T. M. Porto Editora, 1991.

BOULTER, C. J.; GILBERT, J. K. Argument and science education. In: COSTELLO, P. J. M.; MITCHELL, S. (eds.). Competing and consensual voices: the theory and pratice of argument. Clevedon: Multilingual Matters LTD, 1995. p. 84-98.

CAMPOS, L. C.; ARAÚJO, M. S. T. Tensões conceituais e procedimentais nos discursos dos alunos durante atividades experimentais de física. Revista de Ensino de Ciências e 
Matemática, v. 10, n. 3, p. 223-242, 2019. Disponível em:

https://doi.org/10.26843/rencima.v10i3.1481. Acesso em: 19 fev. 2020.

COMPIANI, M. As Geociências no Ensino Fundamental: um estudo de caso sobre o tema "A formação do Universo". 216f. 1996. Tese (Doutorado em Educação, Área de Concentração: Metodologia do Ensino) - Faculdade de Educação da Universidade Estadual de Campinas, Campinas, 1996.

GALIAZZI, G., M. D. C., ROCHA, J. M. B.; SCHMITZ, L. C.; SOUZA, M.L.; GIESTA, S.; GONÇALVES, F. P. Objetivos das atividades experimentais no ensino médio: a pesquisa coletiva como modo de formação de professores de ciências. Ciência \& Educação (Bauru), v. 7, n. 2, p. 249-263, 2001. Disponível em: http://dx.doi.org/10.1590/S1516-

73132001000200008. Acesso em: 19 mar. 2019.

GENTIL, V.; Corrosão. LTC - Livros Técnicos e Científicos Editora: Rio de Janeiro, 2007.

GONÇALVES, F. P.; GALIAZZI, M. C. A Natureza das Atividades Experimentais no Ensino de Ciências: um Programa de Pesquisa Educativa nos Cursos de Licenciatura. In: MORAES, R.; MANCUSO, R. (orgs.). Educação em Ciências: produção de Currículos e Formação de Professores. $2^{a}$ ed. ljuí: Ed. Unijuí, 2006.

HODSON, D. Hacia un enfoque más crítico del trabajo de laboratório. Enseñanza de las ciências, n. 12, v. 3, p. 299-313, 1994. Disponível em: https://www.raco.cat/index.php/Ensenanza/article/view/21370. Acesso em: 24 out. 2019

LEAL, R. R.; SCHETINGER, M. R. C.; PEDROSO, G. B. Experimentação Investigativa em Eletroquímica e Argumentação no Ensino Médio. Revista de Ensino de Ciências e Matemática, v. 10, n. 6, p. 142-162, 2019. Disponível em: https://doi.org/10.26843/rencima.v10i6.2009. Acesso em: 19 fev. 2020.

MONTEIRO, M. A. A.; TEIXEIRA, O. P. B. Uma análise das interações dialógicas em aulas de ciências nas séries iniciais do ensino fundamental. Investigações em Ensino de Ciências, v. 09, n. 03, p. 243-263, 2004. Disponível em:

https://www.if.ufrgs.br/cref/ojs/index.php/ienci/article/view/528/324. Acesso em: 09 ago. 2019.

MORAES, R.; GALIAZZI, M. C.; RAMOS, M. G. Pesquisa em sala de aula: fundamentos e pressupostos. In: MORAES, R.; LIMA, V. M. R. (orgs.). Pesquisa em sala de aula: tendências para a educação em novos tempos. Porto Alegre: EDIPUCRS, p. 9-23, 2002.

OLIVEIRA, J. R. S. A Perspectiva Sócio-histórica de Vygotsky e suas Relações com a Prática da Experimentação no Ensino de Química. ALEXANDRIA Revista de Educação em Ciência e Tecnologia, v. 3, n. 3, p. 25-45, 2010. Disponível em:

https://periodicos.ufsc.br/index.php/alexandria/article/view/38134/29083. Acesso em: 29 jan. 2020.

OLIVEIRA, J. R. S. Contribuiç̧̃̃es e abordagens das atividades experimentais no ensino de ciências: reunindo elementos para a prática docente. Acta Scientiae, v. 12, n. 01, p. 139-153, 2010. Disponível em: http://www.periodicos.ulbra.br/index.php/acta/article/view/31/28. Acesso em: 24 out. 2016.

VIEIRA, R. D.; NASCIMENTO, S. S. Uma proposta de critérios marcadores para identificação de situações argumentativas em salas de aulas de ciências. Caderno Brasileiro de Ensino de 
Física, v. 26, n. 1, p. 81-102, 2009. Disponível em: https://doi.org/10.5007/21757941.2009v26n1p81. Acesso em: 09 ago. 2019.

VYGOTSKY, L. S. A construção do Pensamento e da Linguagem. São Paulo: Martins Fontes, 2001.

VYGOTSKY, L. S. A formação social da mente. 4 ed. São Paulo: Martins Fontes, 1991. 